Research Article

\title{
Clusterin Silencing in Prostate Cancer Induces Matrix Metalloproteinases by an NF- $\kappa$ B-Dependent Mechanism
}

\author{
Martina Bonacini $\left(\mathbb{D},{ }^{1}\right.$ Aide Negri $\mathbb{D}^{2},{ }^{2}$ Pierpaola Davalli $\left(\mathbb{D},{ }^{3}\right.$ Valeria Naponelli $\mathbb{D}^{2,4}$ \\ Ileana Ramazzina $\mathbb{D}^{2,4}$ Chiara Lenzi $\mathbb{D}^{2},{ }^{2}$ Saverio Bettuzzi $\mathbb{D}{ }^{2,4,5}$ and Federica Rizzi $\mathbb{D}^{2,4,5}$ \\ ${ }^{1}$ Unit of Clinical Immunology, Allergy and Advanced Biotechnologies, Azienda Unità Sanitaria Locale-IRCCS di Reggio Emilia, \\ Reggio Emilia 42122, Italy \\ ${ }^{2}$ Department of Medicine and Surgery, University of Parma, Parma 43126, Italy \\ ${ }^{3}$ Department of Biomedical, Metabolic and Neural Sciences, University of Modena and Reggio Emilia, Modena 41125, Italy \\ ${ }^{4}$ Centre for Molecular and Translational Oncology (COMT), University of Parma, Parma 43124, Italy \\ ${ }^{5}$ National Institute of Biostructure and Biosystems (INBB), Viale Medaglie d'Oro, Rome 00136, Italy
}

Correspondence should be addressed to Federica Rizzi; federica.rizzi@unipr.it

Received 21 January 2019; Revised 31 May 2019; Accepted 23 August 2019; Published 6 December 2019

Academic Editor: Vincenzo Coppola

Copyright (c) 2019 Martina Bonacini et al. This is an open access article distributed under the Creative Commons Attribution License, which permits unrestricted use, distribution, and reproduction in any medium, provided the original work is properly cited.

\begin{abstract}
Clusterin (CLU) is a stress-activated glycoprotein, whose expression is altered both in inflammation and cancer. Previously, we showed that abrogation of CLU expression in cancer-prone mice (TRAMP) results in the enhancement of tumor spreading and homing, concomitant with an enhanced expression of NF- $\kappa \mathrm{B}$. In the present paper, we carried out an extensive experimental work by utilizing microarray gene expression data, as well as in vitro and in vivo models of prostate cancer (PCa). Our results demonstrated that (i) CLU expression is significantly downregulated in human PCa and inversely correlates with the expression of p65 in metastases; (ii) CLU overexpression in PCa cells reduces the Ser $_{536}$ phosphorylation of p65, inhibits NF- $\kappa$ B nuclear translocation, and reduces the transcription of matrix metalloproteinase-9 and metalloproteinase-2 (MMP-9 and MMP-2). Conversely, CLU silencing promotes NF- $\kappa \mathrm{B}$ activation and transcriptional upregulation of MMP-9; and (iii) expression and activity of MMP-2 and MMP-9 are increased in $\mathrm{CLU}^{-/-}$mice (CLUKO) and in TRAMP/CLUKO mice in comparison to their relative $\mathrm{Clu}^{+/+}$littermates. Taken together, our data support the hypothesis that CLU downregulation, an early and relevant event in PCa onset, may inhibit NF- $\kappa$ B activation and limit the execution of a transcriptional program that favor the disease progression towards a metastatic stage.
\end{abstract}

\section{Introduction}

Chronic infection and inflammation have been recognized to start cell transformation and promote cancer development [1]. The transcription factor NF- $\kappa \mathrm{B}$ is the main trigger of proinflammatory processes and key molecular link of inflammation to tumor initiation and progression $[2,3]$. NF$\kappa \mathrm{B}$ is also required to sustain a proinflammatory microenvironment that facilitates extracellular matrix (ECM) degradation and tumor cell dissemination in prostate cancer (PCa) $[4,5]$. Clusterin (CLU) is a secreted glycoprotein known to be involved both in inflammation and cancer
[6-8]. CLU may be retained inside the cell as a consequence of various stress-activated mechanisms, which include retrotranslocation from the endoplasmic reticulum, alternative splicing, alternative transcription initiation, and internalization from the extracellular compartment $[9,10]$. Intracellular CLU interferes with relevant cell signaling pathways, including NF- $\kappa \mathrm{B}[11,12]$. In vivo CLU has antiinflammatory functions; indeed, in the experimental model of induced autoimmune myocarditis and pancreatitis, CLU knockout mice (CLUKO) show signs of more severe inflammation and cellular pathology than CLU-expressing wild-type controls (WT) $[13,14]$. CLU expression is altered 
in many tumors including $\mathrm{PCa}$, although conflicting data about its tumor suppressive or tumor permissive role have been published [8]. We and other authors have observed that CLU is downregulated in human PCa progression $[15,16]$ and in tumors arising in the TRansgenic Adenocarcinoma of the Mouse Prostate (TRAMP) model [17, 18]. Moreover, CLUKO mice are more susceptible than WT to chemically induced skin tumorigenesis, suggesting that CLU might negatively modulate epithelial cell transformation [19]. When CLUKO mice were crossed with TRAMP to obtain TRAMP/CLUKO mice, we found that tumor spreading and metastases occurred earlier in animals lacking CLU expression [20]. Cancerous lesions of TRAMP prostates are positive for NF- $\kappa \mathrm{B}$ and Ki67 staining in comparison to WT. Of note, an even stronger expression of these proteins was detected in the cancerous lesions of age-matched TRAMP/ CLUKO [20], suggesting the hypothesis that one possible mechanism by which CLU slows down tumor spreading in TRAMP mice might also involve limiting NF- $\kappa \mathrm{B}$ activity. The aim of the present work is to challenge the aforementioned hypothesis by an articulated experimental approach that started from examining the expression of p65 and CLU in large microarray dataset retrieved in GEO (Gene Expression Omnibus) which included expression profiling of normal, prostate primary tumors, and metastatic tissue. Then, we evaluated the changes of NF- $\kappa \mathrm{B}$ expression and activity in human PCa cells following either CLU overexpression or silencing. Finally, we measured in prostate tissue obtained from WT, CLUKO, TRAMP, and TRAMP/ CLUKO, the expression and activity of ECM metalloproteinases (MMP-2 and MMP-9) that are known to be involved in tumor dissemination being regulated by the NF$\kappa \mathrm{B}$ pathway.

\section{Materials and Methods}

2.1. Public Domain Data. mRNA expression levels of the human prostate sample from microarray dataset GSE6919 were analyzed with GEO2R web tool (http://www.ncbi. nlm.nih.gov/geo/geo2r/). GSE6919 was performed on the Affymetrix Human U95 Version 2 Array platform (GPL8300), which comprises the expression profiles of the following human specimens: 18 normal prostates, 63 normal prostates adjacent to the tumor, 65 primary prostate tumors, and 25 prostate metastases. Expression levels of CLU and p65 were compared between primary tumors and metastatic tissues. The Benjamini and Hochberg false discovery rate method was used to correct for multiple comparisons.

2.2. Cell Culture. PC3 cells were purchased from the American Tissue Culture Collection and were routinely grown in Ham's F12:MEM medium $(1: 1)$. The culture media were supplemented with $10 \%$ foetal bovine serum (Lonza, Basel, CH), 2 mM L-glutamine, $100 \mathrm{U} / \mathrm{mL}$ penicillin, and $100 \mu \mathrm{g} / \mathrm{mL}$ streptomycin. The cells were incubated at $37^{\circ} \mathrm{C}$ under a $5 \% \mathrm{CO}_{2}$ atmosphere and harvested by trypsin/ EDTA (Sigma-Aldrich, Steinheim, DE). The full-length human CLU coding sequence was previously cloned into the bicistronic expression vector pIREShyg1 (U89672, Clontech, Oxford, UK) [21]. PC3 $3_{\mathrm{CLU}}$ and $\mathrm{PC} 3$ mock were generated by clonal selection and maintained as previously described [21].

2.3. CLU Transient Overexpression. PC3 cells were seeded at a density of $7.5 \times 10^{4}$ cells $/ \mathrm{mL}$ and transfected with $4 \mu \mathrm{g}$ of pIRES-CLU or pIREShyg1 (mock) using FuGene ${ }^{\circledR}$ HD Transfection Reagent (Promega, Madison, WI). Cells were harvested 24 or 48 hours after transfection and used for mRNA and protein extraction.

2.4. CLU Silencing. PC3 cells were seeded at a density of $2 \times 10^{5}$ cells $/ \mathrm{mL}$ and transfected with $100 \mathrm{nM}$ CLU siRNA (5'-GCAGCAGAGUCUUCAUCAU-3' Ambion, Austin, TX) using the TransIT-TKO Transfection Reagent (Mirus Bio, Madison, WI). A universal scrambled sequence called NC siRNA (Integrated DNA Technologies, Coralville, IA) was used as negative control. Cells were harvested at 24 and 48 hours after transfection and used for RNA and protein extraction.

2.5. Genetically Modified Mice. Male and female TRAMP mice heterozygous for the SV40 transgene were obtained from Jackson Laboratories (Bar Harbor, ME, USA), maintained in a $\mathrm{C} 57 \mathrm{Bl} / 6$ background and screened according to Greenberg et al. [22]. CLU-deficient mice (CLUKO) backcrossed to the $\mathrm{C} 57 \mathrm{Bl} / 6$ strain for more than 10 generations were obtained breeding heterozygous parents and genotyping the offspring for CLU expression [13]. Female TRAMP mice were mated with homozygous (CLUKO) male mice to obtain TRAMP/CLU ${ }^{+/-}$mice. Then, TRAMP/CLU ${ }^{+/-}$females were mated with heterozygous $\left(\mathrm{CLU}^{+/}\right)$male mice to obtain TRAMP/CLUKO mice. Mice were housed in a standard animal facility under controlled environmental conditions $\left(22 \pm 2^{\circ} \mathrm{C}, 12\right.$ hours light/dark cycle) and were allowed free access to food and water. For the immunohistochemical detection of p65, a total of 12 mice, 3 for each experimental group, were sacrificed at 12 and 24 weeks of age, the prostates were excised, fixed in $10 \%$ (vol/vol) neutral-buffered formalin at $4^{\circ} \mathrm{C}$ overnight, and processed to paraffin using standard procedures for immunohistochemical analysis. For the zymography assay, a total of 12 male mice, 3 for each experimental group (WT, CLUKO, TRAMP, and TRAMP/ CLUKO) were euthanized at 36 weeks of age. Prostates were excised, snap-frozen in liquid nitrogen, and stored at $-80^{\circ} \mathrm{C}$ until use. All the experimental procedures involving transgenic mice were approved and conducted in accordance with the Italian law (D.lgs 26/2014).

2.6. RNA Extraction, cDNA Preparation, and Real-Time RTPCR ( $q P C R)$. RNA was extracted from human cells or prostate samples using TRIzol ${ }^{\circledR}$ reagent (Fisher Molecular Biology, Rome, IT) and purified with the PureLink ${ }^{\circledR}$ RNA Mini Kit (Fisher Molecular Biology, Rome, IT). cDNA was prepared using the RevertAid First Strand cDNA Synthesis kit (Thermo Fisher Scientific, Waltham, MA) following the 
manufacturer's instructions [23]. Primers information is reported in Table 1. The human or murine glyceraldehyde 3phosphate dehydrogenase (hGAPDH and $\mathrm{mGAPDH}$ ) was used as the reference gene. Normalized CT $(\Delta \mathrm{CT})=\mathrm{CT}$ (target gene)-CT (GAPDH) when the indicated $\Delta \Delta \mathrm{CT}$ values were used for calculation of relative expression by the $2^{-\Delta \Delta \mathrm{CT}}$ method, where $\Delta \Delta \mathrm{CT}=\Delta \mathrm{CT}$ target sample $-\Delta \mathrm{CT}$ control sample.

2.7. Protein Extraction, SDS-PAGE, and Western Blot (WB) Analysis. Cells were lysed in the RIPA buffer $(50 \mathrm{mM}$ Tris$\mathrm{HCl} \mathrm{pH} 7.4,100 \mathrm{mM} \mathrm{NaCl}$, and $1 \%$ Triton X-100) supplemented with protease and phosphatase inhibitors (SigmaAldrich, Steinheim, DE). Protein concentration was determined using the Bio-Rad DC Protein Assay (Bio-Rad, Berkley, CA). $70 \mu \mathrm{g}$ of proteins/lane was separated on $12 \%$ SDS-PAGE gel, transferred to PVDF membranes, routinely stained with red Ponceau for loading and transfer control, and probed for 16 hours at $4^{\circ} \mathrm{C}$ by means of the following antibodies: mouse monoclonal anti-CLU, dilution $1: 1000$ (Millipore, Billerica, MA); rabbit monoclonal anti-p-p65 ${ }_{\text {S536, }}$ dilution $1: 500$, and mouse monoclonal anti-p65, dilution 1 : 1000 (Cell Signaling, Technology, Denver, MA); mouse monoclonal anti- $\beta$-actin, dilution 1:200 (Santa Cruz Biotechnology, Dallas, TX) and rabbit monoclonal anti-I $\kappa \mathrm{B} \alpha$, dilution 1:1000 (Cell Signaling Technology, Denver, MA); rabbit monoclonal anti-IKK $\beta$, dilution 1:1000 (Cell Signaling Technology, Denver, MA); and rabbit polyclonal antiAkt, dilution 1:1000 (Cell Signaling Technology, Denver, MA). Membranes were incubated with suitable secondary antimouse or antirabbit IgG antibodies conjugated to horseradish peroxidase, dilution 1:5000 and 1:20000, respectively, (Sigma-Aldrich, Steinheim, DE) and developed by the Chemiluminescence Blotting Substrate, POD (Roche, Basel, $\mathrm{CH}$ ). Quantification of band intensities was conducted using Quantity One ${ }^{\circledR}$ software (Bio-Rad, Berkley, CA). Intensity of each band was normalized for $\beta$-actin intensity from the same sample on the same blot.

2.8. Immunocytochemical Analysis. $\mathrm{PC} 3_{\text {mock }}$ and $\mathrm{PC} 3_{\mathrm{CLU}}$ cells were cultured on a glass cover slip at a density of $0.75 \times 10^{5} \mathrm{cell} / \mathrm{mL}$ for 72 hours, fixed and permeabilized with $1: 1$ methanol:acetone (for CLU detection), or fixed in $4 \%$ paraformaldehyde and permeabilized with methanol (for p-p65 ${ }_{5536}$ detection). After blocking in horse serum 3\% (vol/ vol) in Dulbecco's modified phosphate-buffered saline (DPBS), cells were incubated with a mouse monoclonal antiCLU antibody, dilution 1:50 (Millipore, Billerica, MA) or with a rabbit polyclonal anti-p-p65, dilution 1:200 (Santa Cruz, Dallas, TX) in 3\% BSA in D-PBS solution for 1 hour, conjugated with fluorescent anti-mouse Alexa Fluor 488 or anti-rabbit Alexa Fluor 568 antibodies (Invitrogen, Carlsbad, CA), dilution $1: 200$ in $3 \%$ bovine serum albumin (BSA), stained with 4',6-diamidino-2-phenylindole (DAPI) (Biotium Inc, Hayward, CA), and embedded in Mowiol (Sigma-Aldrich, Steinheim, DE). Fluorescence images were acquired with the 200 inverted fluorescence microscope equipped with an AxioCam HRc camera and the AxioVision 4.8 software (all from Carl Zeiss, Göttingen, DE).

2.9. Cell Proliferation Assay. Cell proliferation of $\mathrm{PC} 3_{\text {mock }}$ and $\mathrm{PC} 3_{\mathrm{CLU}}$ cells was evaluated by crystal violet assay. Briefly, cells were seeded at a density of $7.5 \times 10^{4} \mathrm{cell} / \mathrm{mL}$. At 24-48-72-96 hours, the medium was removed and the cells were fixed with $4 \%$ paraformaldehyde for $20 \mathrm{~min}$ at room temperature. Fixed cells were stained with $0.5 \%$ crystal violet (Sigma-Aldrich, Steinheim, DE) in 20\% methanol for $15 \mathrm{~min}$ and then washed and dissolved in a solution of $0.1 \mathrm{M}$ sodium citrate in ethanol $50 \%, \mathrm{pH} 4.2$. The absorbance at $540 \mathrm{~nm}$ was measured using a biophotometer (Eppendorf, Hamburg, $\mathrm{DE})$.

2.10. Cell Cycle Analysis. $\mathrm{PC} 3_{\text {mock }}$ and $\mathrm{PC} 3_{\mathrm{CLU}}$ cells were collected, washed in $1 \%$ BSA in PBS, fixed with $70 \%$ cold ethanol, and stored at $-20^{\circ} \mathrm{C}$ overnight. DNA staining was performed following resuspension of the pellet in the buffer containing $20 \mu \mathrm{g} / \mathrm{mL}$ propidium iodide (Invitrogen, Milan, Italy) and $0.1 \mathrm{mg} / \mathrm{mL}$ RNase (Sigma-Aldrich, Steinheim, DE) in PBS. The cell suspension was then analyzed for DNA content and cell cycle phase distribution by FACS analysis (Becton Dickinson, Franklin Lakes, NJ). The data were analyzed using the CellFIT 3.0.1 software (Becton Dickinson, Franklin Lakes, NJ).

2.11. NF- $\kappa B$ Activity Luciferase Assay. $12.5 \times 10^{4}$ cells $/ \mathrm{mL}$ were seeded and transfected with $0.2 \mu \mathrm{g}$ of $\mathrm{pNF} \kappa \mathrm{B}-\mathrm{LUC}$ reporter plasmid (631904, Clontech, Mountain View, CA) or cotransfected with $0.1 \mu \mathrm{g}$ of $\mathrm{pNF} \kappa \mathrm{B}-\mathrm{LUC}$ and $0.1 \mu \mathrm{g}$ of pIRES-CLU or pIREShyg1 or 1 pmol of CLU siRNA or NC siRNA using Lipofectamine ${ }^{\circledR} 3000$ (Thermo Fisher Scientific, Waltham, MA). The luciferase activity was measured 24 hours after transfection using the Britelite ${ }^{\mathrm{TM}}$ plus reactive (PerkinElmer, Waltham, MA) using the EnSpire ${ }^{\circledR}$ Multimode Plate Readers (PerkinElmer, Waltham, MA) and normalized to the total protein content after checking for equal transfection efficiency. The results are representative of three independent experiments run in triplicate.

2.12. Immunohistochemical Analysis. Paraffin-embedded tissue sections $(5 \mathrm{~mm})$ mounted onto glass slides were hydrated in xylene, graded alcohol. Antigen retrieval was performed by microwave $(5 \mathrm{~min}$ at $700 \mathrm{~W})$ using a sodium citrate buffer $(10 \mathrm{mM}, \mathrm{pH}$ 6.0). Endogenous peroxidase activity was quenched with $3 \% \mathrm{H}_{2} \mathrm{O}_{2}$. Nonspecific binding was blocked with swine serum diluted $1: 10$ in BSA $1 \%$. Immunostaining was performed using the mouse monoclonal anti-p65 antibody dilution 1:50 in BSA 1\% (Santa Cruz Biotechnology, Dallas, TX) and incubated for $1 \mathrm{~h}$ at room temperature. From the secondary antibody to the chromogen reaction, a Universal LSAb2 HRP kit (DakoCytomation, Glostrup, DK) was used according to the manufacturer's instruction as previously described [20]. 
TABLE 1: Sequences of the primers used in qPCR.

\begin{tabular}{|c|c|c|c|c|}
\hline Gene & Primer for $5^{\prime} \longrightarrow 3^{\prime}$ & Primer rev $5^{\prime} \longrightarrow 3^{\prime}$ & $T_{\mathrm{a}}\left({ }^{\circ} \mathrm{C}\right)$ & Cycle \\
\hline hCLU & TGATCCCATCACTGTGACGG & GCTTTTTGCGGTATTCCTGC & 60 & 40 \\
\hline hMMP-2 & AGCGCTACGATGGAGGCGCTA & AGAAGGTGTTCAGGTATTGCACTGC & 60 & 40 \\
\hline hMMP-9 & GCGCCAGCGAGGTGGACCGGA & ACGGGAGCCCTAGTCCTCAGGGCAC & 65 & 40 \\
\hline hGAPDH & AACCTGCCAAATATGATGAC & TTGAAGTCAGAGGAGACCAC & 60 & 40 \\
\hline mMMP-2 & GGTGGTGGTCATAGCTACTTC & TGAAGATGATAGGGCCCGTG & 60 & 40 \\
\hline mMMP-9 & TTGAGTCCGGCAGACAATCC & ACTTCCAGTACCAACCGTCC & 60 & 40 \\
\hline mGAPDH & TCAAGCTCATTTCCTGGTAT & GTCCAGGGTTTCTTACTCCT & 60 & 40 \\
\hline
\end{tabular}

2.13. Gelatin Zymography. Frozen mouse prostates were finely grinded with liquid nitrogen and lysed in a lysis buffer (25 mM Tris-HCl pH 7.4, $100 \mathrm{mM} \mathrm{NaCl}, 1 \%$ IGEPAL ${ }^{\circledR}$ CA-630, Sigma-Aldrich, Steinheim, DE) supplemented with 1:100 protease and phosphatase inhibitors (Sigma-Aldrich, Steinheim, DE). Protein concentration was determined using the Bio-Rad DC Protein assay (BioRad, Berkley, CA). $30 \mu \mathrm{g}$ of proteins/lane was separated on $8 \%$ SDS-PAGE gel containing $0.1 \%$ porcine skin gelatine (Sigma-Aldrich, Steinheim, DE). Gels were washed for $30 \mathrm{~min}$ at room temperature in a washing buffer $(2.5 \%$ Triton X-100) and incubated for 18 hours at $37^{\circ} \mathrm{C}$ in an activation buffer $(20 \mathrm{mM}$ Tris- $\mathrm{HCl} \mathrm{pH} 8.0,5 \mathrm{mM} \mathrm{CaCl}$, and $150 \mathrm{mM} \mathrm{NaCl}$ ). Gels were stained with $0.1 \%$ Coomassie Brilliant Blue R250 (Sigma-Aldrich, Steinheim, DE) and destained with a destain solution (10\% ethanol and 10\% acetic acid).

2.14. Immunoprecipitation Assay. $500 \mu \mathrm{g}$ of intracellular protein from $\mathrm{PC} 3_{\text {mock }}$ and $\mathrm{PC} 3_{\mathrm{CLU}}$ cells was precleared with $50 \mu \mathrm{L}$ of protein $\mathrm{G}$-agarose beads (Roche, Basel, $\mathrm{CH}$ ) for $30 \mathrm{~min}$ at $4^{\circ} \mathrm{C}$ with gentle rotation. Then, the lysates were incubated for 18 hours at $4^{\circ} \mathrm{C}$ with $5 \mu \mathrm{g}$ of the following antibodies: mouse monoclonal anti-CLU (05-354, Millipore, Billerica, MA), mouse monoclonal anti-p65 (\#6956, Cell Signaling Technology, Denver, MA), and normal mouse IgG (NI03, Millipore, Billerica, MA). $50 \mu \mathrm{L}$ of protein G-Agarose beads (Roche, Basel, $\mathrm{CH}$ ) was added and incubated for 4 hours at $4^{\circ} \mathrm{C}$ with gentle rotation. After centrifugation, immune-precipitated pellets were washed four times with icecold RIPA buffer, dissolved in the Laemmli buffer added with $100 \mathrm{nM}$ dithiothreitol, and heated at $100^{\circ} \mathrm{C}$ for $3 \mathrm{~min}$ for reverse cross-link.

2.15. Statistical Analyses. The IBM SPSS statistical package (International Business Machines Corporation, Armonk, NY, USA, version 24) was used. Normal distribution of variables was checked by means of the KolmogorovSmirnov test. Statistics of variables included mean\pm standard deviation (SD), the unpaired Student's $t$-test (luciferase assay and qPCR), and the Mann-Whitney $U$ test (qPCR data). Statistical significance was set at $p<0.05$. Pearson's correlation test on microarray data $(n=80)$ was performed with GraphPad Prism 6 software. Details on the specific test used are reported in the figure legend of each experiment.

\section{Results}

3.1. CLU and p65 Are Significantly Inversely Correlated in Human Samples of PCa Metastases. The GEO2R web tool was used to compare the mRNA expression of CLU and p65 in the microarray dataset GSE6919, which comprises primary and metastatic prostate tumors, normal prostate tissue adjacent to tumor, and normal prostate tissue from healthy donors (Figure 1(a)). The highest expression of CLU was found in normal prostate tissue and gradually decreased in normal tissue adjacent to the tumor and primary prostate tumor, reaching the lowest value in metastatic samples. A statistically significant decrease in CLU along with a significant increase in p65 expression was observed when tissues from primary and metastatic PCa were compared (Figure 1(a)). Moreover, in primary tumor and metastases, the expression of CLU and p65 is inversely correlated (Figure 1(b)).

3.2. NF- $\kappa B$ Transcriptional Activity Is Inhibited by CLU Overexpression. At least five CLU ( $\left.\mathrm{PC} 3_{\mathrm{CLU}}\right)$ and five mock clones $\left(\mathrm{PC} 3_{\text {mock }}\right.$ ) were analyzed for CLU content, cell morphology, cell proliferation, and percentage of distribution of cells in different phases of the cell cycle. CLU mRNA is significantly more expressed in $\mathrm{PC} 3_{\mathrm{CLU}}$ than in $\mathrm{PC} 3_{\text {mock }}$ (Figure 2(a)). Both the precursor form of $64 \mathrm{kDa}$ (psCLU) and the mature form of $40 \mathrm{kDa}(\mathrm{sCLU})$ were expressed at a higher level in cell lysates and culture media of PC $3_{\mathrm{CLU}}$ compared to PC $3_{\text {mock }}$, although the intensity of the WB blot bands shows some differences depending on the single clone analyzed (Figure 2(c)-S1). These results have also been confirmed in a polyclonal population obtained by pooling together several PC $3_{\text {CLU }}$ clones different from those analyzed individually (Figure 2(c)). The immunofluorescence analyses confirmed that CLU is significantly more expressed in PC $3_{\mathrm{CLU}}$ than in PC $3_{\text {mock }}$ and localizes to the cytoplasm (Figure 2(b)). PC $3_{\mathrm{CLU}}$ cells are more round shaped than $\mathrm{PC} 3$ mock (Figure S2(a)) and grow slower than $\mathrm{PC} 3$ mock (Figure S2(b)). We also measured an impairment in the cell cycle distribution, which is consistent with a slowdown of the progression between the G0/ $\mathrm{G} 1$ and the $\mathrm{S}$ phase in $\mathrm{PC} 3_{\mathrm{CLU}}$ compared to $\mathrm{PC} 3_{\text {mock }}$ (Figure S2(c)). When, in the same clones, we measured the expression of NF- $\kappa \mathrm{B}$ (p65 total) and active NF- $\kappa \mathrm{B}\left(\mathrm{p}-\mathrm{p} 65_{\mathrm{S} 536}\right)$, we detected a reduction of $\mathrm{p}-\mathrm{p} 65_{\mathrm{S} 536}$ in $\mathrm{PC} 3_{\mathrm{CLU}}$ compared to controls (Figure 2(c)-S1), also in the polyclonal samples that ideally represent the averaged trend of many cell clones (Figure 2(c)). The immunocytochemical (IC) analysis showed that $\mathrm{p}-\mathrm{p} 65_{\mathrm{S} 536}$ is reduced in $\mathrm{PC} 3_{\mathrm{CLU}}$ compared to $\mathrm{PC} 3_{\text {mock }}$, 


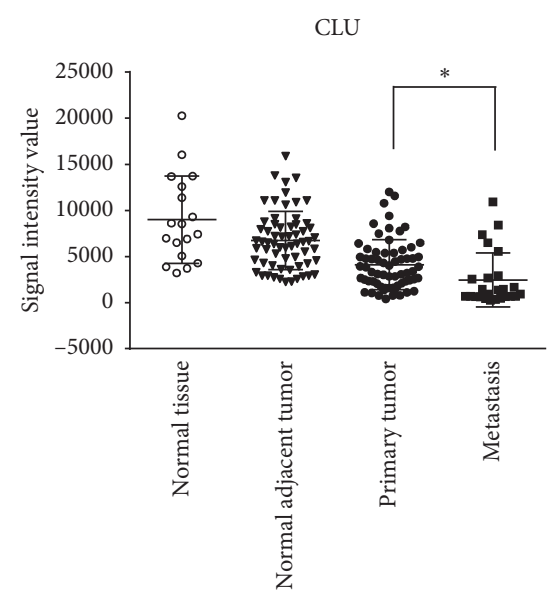

(a)

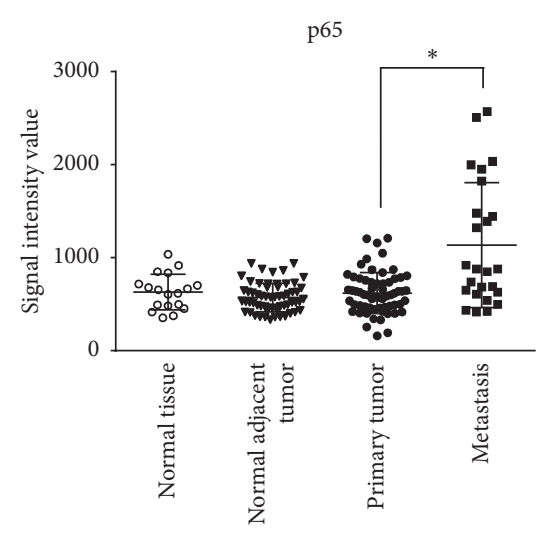

(b)

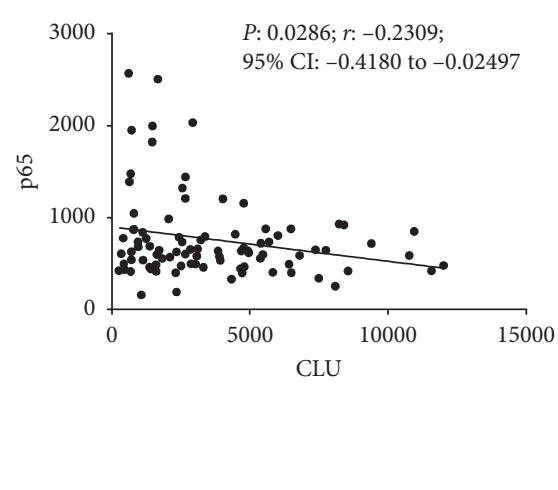

(c)

FIGURE 1: Expression of CLU and p65 mRNA in human prostate tissue samples. (a) mRNA expression of CLU and (b) p65 in human normal prostate tissue $(\mathrm{O})$, normal prostate tissue adjacent to the tumor $(\boldsymbol{\nabla})$, primary tumor $(\bullet)$, and metastasis $(\boldsymbol{\square})$ downloaded from GSE6919 dataset. The GEO2R tool was used to test differences in the mRNA levels between primary tumor and metastasis. Horizontal lines show the mean \pm SD. ${ }^{*} p<0.0001$ ( $t$-test corrected for multiple comparison by the Benjamini and Hochberg method). (c) Dot plot visualization of the inverse correlation between the expression of CLU and p65 in human tumor samples (primary tumors and metastasis) from the GSE6919 dataset. Correlation coefficient was evaluated by Pearson's correlation test $(n=80)$.

where, in the contrary, an intense staining was found in the cell nuclei (Figure 3(a)). The transcriptional activity of NF- $\kappa \mathrm{B}$ measured by the luciferase assay is reduced in $\mathrm{PC} 3_{\mathrm{CLU}}$ compared to $\mathrm{PC} 3_{\text {mock }}$ (Figure 3(b)). Consistently, the expression of ECM-degrading enzymes, such as MMP-2 and MMP-9, whose expression is transcriptionally controlled by $\mathrm{NF}-\kappa \mathrm{B}$, is significantly lower in $\mathrm{PC}_{\mathrm{CLU}}$ clones compared to PC $3_{\text {mock }}$ (Figure 3(c)). Similarly, CLU expression (psCLU and sCLU) was increased in cell lysates and in growth media of PC 3 cells transiently transduced with p-IRES-CLU for 24 and 48 hours (Figure 4(a), lanes C24 and C48) in comparison to cells receiving the empty vector (Figure 4(a), lanes M24 and M48). In the same cells, $\mathrm{p}-\mathrm{p} 65_{\mathrm{S} 536}$ is significantly reduced (Figure 4(b), lanes C24 and C48) compared to mock (Figure 4(b), lanes M24 and M48) and is accompanied by a reduction of the transcriptional activity of NF- $\kappa \mathrm{B}$, measured by the luciferase assay (Figure $4(\mathrm{c})$ ). A slight reduction in $\mathrm{I} \kappa \mathrm{B} \alpha$ expression along with a significant decrease in IKK $\beta$ and Akt was detected in C48 in comparison to M48 (Figure 4(b)).

3.3. CLU Silencing Increases NF- $\kappa B$ Transcriptional Activity. CLU expression was almost completely abrogated in PC3 cells, starting from 24 and up to 48 hours after CLU siRNA transfection in comparison to negative control (NC) transduced cells (Figure 5(a)). In the same samples, p-p65 5536 increased after 24 hours and much more significantly after 48 hours in CLU siRNA (Figure 5(b), lanes CLU 24 and CLU 48) compared to NC transduced cells (Figure 5(b) lanes NC 24 and NC 48). I $k$ B $\alpha$ and IKK $\beta$ did not change, while a significant increase of Akt was detected in CLU 48 in comparison to NC 48 (Figure 5(b)). By the Luciferase assay, we found that NF- $\kappa \mathrm{B}$ transcriptional activity increased in PC3 cells transduced with CLU siRNA in comparison to NC (Figure 5(c)). Consistently, the expression of MMP-9 mRNA is significantly increased 24 and 48 hours after CLU siRNA transfection in comparison to NC (Figure 5(d)).

3.4. CLU Does Not Prevent NF- $\kappa B$ Activation by means of a Direct Interaction with the p65 Subunit. We investigated whether CLU may physically hide the accessibility of $S_{536}$ to specific kinases such as IKK $\beta$ by direct binding with p65. Therefore, we immune-precipitated (IP) CLU and p65 from $\mathrm{PC} 3_{\mathrm{CLU}}$ and $\mathrm{PC} 3_{\text {mock }}$ cell lysates. Then, we searched for CLU and p65 physical interaction by WB analysis of the IP fractions. CLU was successfully pulled down when the specific anti-CLU antibody was used for immunoprecipitation (IP positive control), as demonstrated by the presence of a band at $64 \mathrm{kDa}$ in the IP fraction (Figure 6(a), upper panel). The result of the immunoprecipitation reaction is specific because no CLU band is detectable in the mouse IgG immunoprecipitated sample (negative control). No bands were detected, instead, when the same membrane was probed with an anti-p65 antibody, indicating that no direct interaction took place between CLU and p65 in $\mathrm{PC}_{\mathrm{CLU}}$ compared to PC $3_{\text {mock }}$ (Figure 6(a), lower panel). Similarly, when the intracellular lysates were immunoprecipitated with an anti-p65 antibody, we were able to detect p65 in the IP fraction (positive control), while no $\mathrm{p} 65$ was detected in the mouse IgG immunoprecipitated sample (negative control) (Figure 6(b), upper panel). No bands were detected, instead, when the same membrane was probed with an anti-CLU antibody (Figure 6(b), lower panel).

3.5. MMP-2 and MMP-9 Gelatinolitic Activity Increased in TRAMP/CLUKO Mice Compared to TRAMP Littermates. By immunohistochemical analysis, we observed that p65 is more expressed in prostate tissues of TRAMP/CLUKO mice 


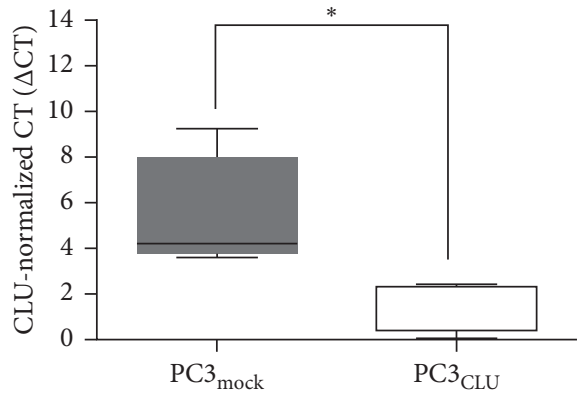

(a)
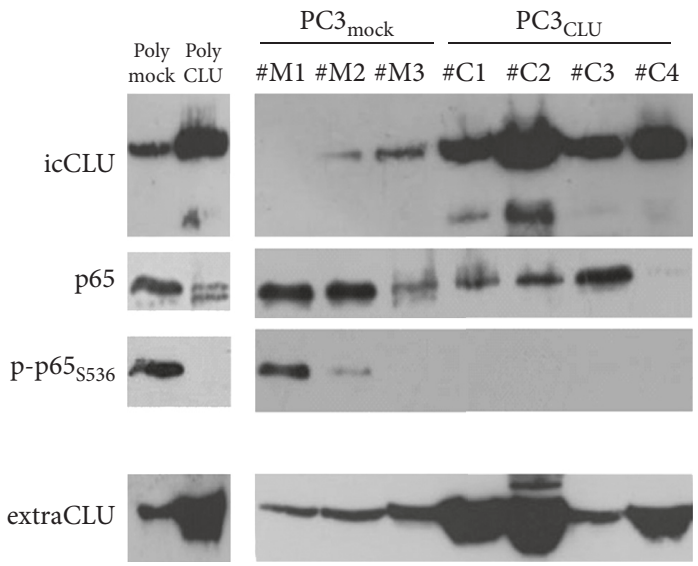

(c)

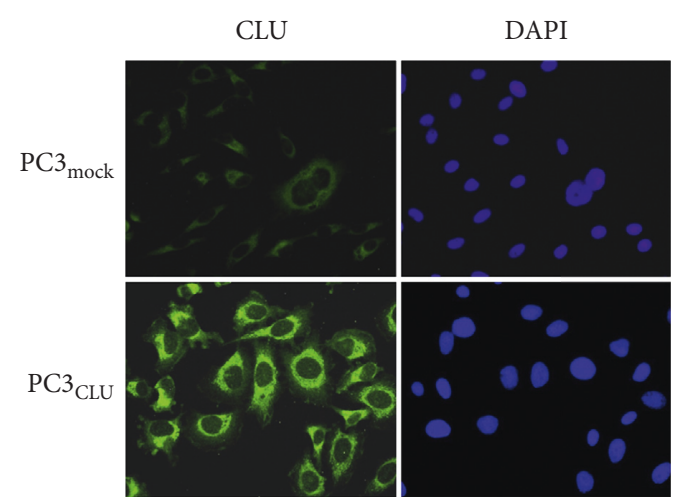

(b)

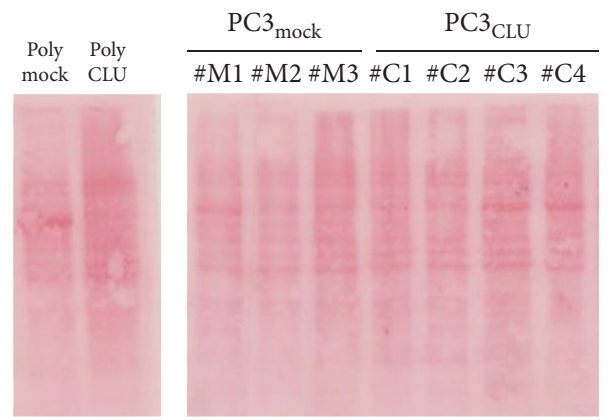

(d)

Figure 2: CLU stable overexpression and p65 expression and phosphorylation in PC3 cells. (a) Quantification of CLU mRNA in PC3 ${ }_{\text {mock }}$ (namely, clones \#M1, \#M2, and \#M3) and PC $3_{\mathrm{CLU}}$ (namely, clones \#C1, \#C2, \#C3, and \#C4) by qPCR. $\triangle \mathrm{CT}$ values have been reported in a box plot graph; the line crossing the boxes represents the median value of the distribution. hGAPDH was used as a housekeeper gene. ${ }^{*} p<0.05$ vs. PC $3_{\text {mock }}$ (the unpaired Student's $t$-test). (b) Subcellular localization of CLU (green fluorescence) in PC $3_{\text {mock }}$ and PC $3_{\mathrm{CLU}}$ cells. Nuclei staining with DAPI (blue fluorescence). The pictures shown refer to \#M2 and \#C2 clones and are representative of all the other analyzed clones. Image magnification was $32 \times$. (c) Quantification of intracellular CLU, p65, and p-p65 5536 proteins by WB analysis in PC3 $3_{\text {mock }}$ (namely, clones \#M1, \#M2, and \#M3), PC3 ${ }_{\mathrm{CLU}}$ (namely, clones \#C1, \#C2, \#C3, and \#C4), and polyclonal samples. (d) Red Ponceau staining was used as loading control. Quantification of CLU protein secreted in cell culture media by WB analysis in PC $3_{\text {mock }}$ (namely, clones \#M1, \#M2, and \#M3), PC3 $3_{\mathrm{CLU}}$ (namely, clones \#C1, \#C2, \#C3, and \#C4), and polyclonal samples. icCLU, intracellular CLU; extraCLU, CLU secreted in culture media; psCLU, uncleaved CLU precursor, $64 \mathrm{kDa}$; sCLU, cleaved mature CLU, $40 \mathrm{kDa}$.

than age-matched TRAMP animals expressing CLU (Figure S3). Then, we proceeded measuring the expression level and the enzymatic activity of MMP-2 and MMP-9 in prostate samples obtained from WT, CLUKO, TRAMP, and TRAMP/CLUKO littermates. The lowest median values of normalized CT for MMP-2 were measured in the CLUKO and TRAMP/CLUKO prostates by qPCR analysis of mRNA expression. The increase in MMP-2 expression is statistically significant when TRAMP/CLUKO is compared with TRAMP (Figure 7(a)). The lowest median values of normalized CT for MMP-9 were measured in CLUKO mice, in which MMP-9 expression is therefore significantly upregulated compared to WT littermates (Figure 7(b)). The enzymatic activity of MMP2 and MMP-9 was assessed by gelatine zymography. A strong increase in MMP-9 and MMP-2 gelatinolitic activity was observed in both CLUKO and TRAMP/CLUKO mice in comparison to WT and TRAMP mice, respectively. The strongest difference was observed for the pro-MMP-9 band, corresponding to the uncleaved precursor protein. Additional bands at lower molecular weight, corresponding to the cleaved active enzymes (aMMP-9 and a-MMP-2), are more expressed in the prostate tissues of animals that lack CLU expression.

\section{Discussion}

Although the adaptive immune system mediates antitumor effects through immune surveillance, many tumors acquire the ability to subvert inflammatory signals to their benefit [4]. NF- $\kappa \mathrm{B}$ is aberrantly activated in the majority of PCa cases, and it is considered the major transcription factor contributing to sustain a proinflammatory, tumor-permissive microenvironment [24]. Although many molecules act as NF- $\kappa \mathrm{B}$ activators, very few proteins are known to negatively interfere with $\mathrm{NF}-\kappa \mathrm{B}$ signaling, a part from $\mathrm{I} \kappa \mathrm{B} s$ proteins, which are the major inhibitors of the pathway. 


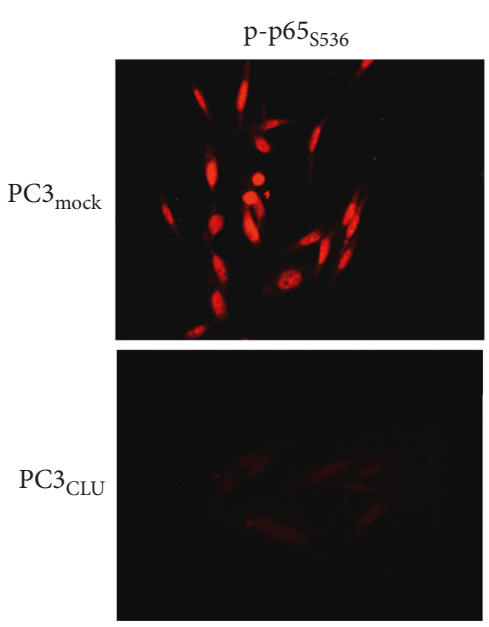

(a)

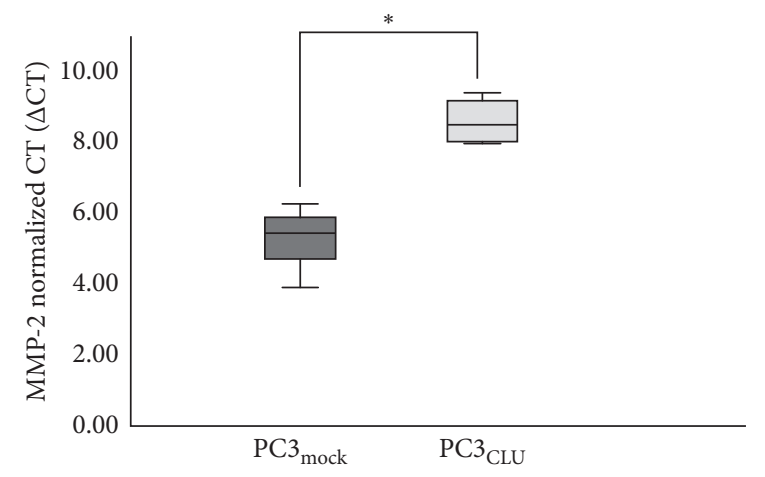

(c)

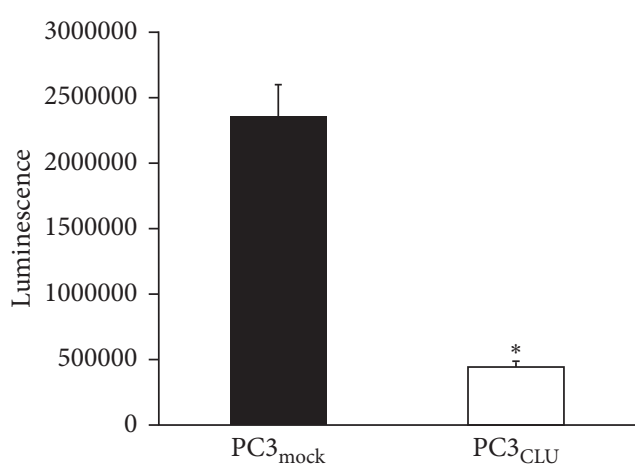

(b)

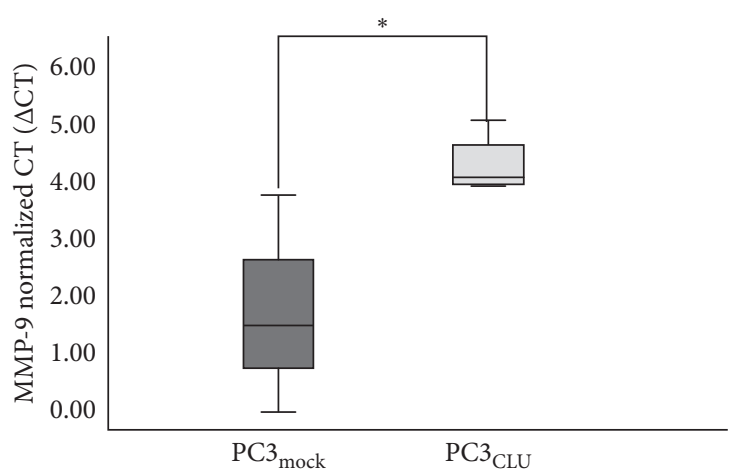

(d)

Figure 3: Effects of CLU stable overexpression on NF- $\kappa$ B activation. (a) Subcellular localization of p-p65 S536 $_{\text {(red fluorescence) in PC } 3_{\text {mock }}}$ and PC $3_{\mathrm{CLU}}$ cells. Nuclei staining with DAPI (blue fluorescence). Image magnification was $32 \times$. The pictures shown refer to \#M2 and \#C2 clones and are representative of all the other analyzed clones. (b) Luciferase assay for NF- $\kappa$ B activity was carried out in PC $3_{\text {mock }}$ (\#M2) and $P C 3_{\mathrm{CLU}}(\# \mathrm{C} 2)$ cells transfected with the reporter vector $\mathrm{pNF} \kappa \mathrm{B}-\mathrm{LUC}$. The assay was performed 24 hours after transfection. Mean normalized data of luminescence (arbitrary units) \pm SD from six replicate wells of three independent experiments are reported on the $Y$ axis. ${ }^{*} p<0.001$ vs. PC $3_{\text {mock }}$ (unpaired Student's $t$-test). (c) Quantification of MMP-2 and MMP-9 mRNA in PC $3_{\text {mock }}$ and PC $3_{C L U}$ clones by qPCR. $\Delta C T$ values are reported on the $Y$ axis. hGAPDH was used as the housekeeper gene. ${ }^{*} p<0.05$ vs. PC $3_{\text {mock }}$ (the Mann-Whitney $U$ test).

CLU is a heavy glycosylated secreted heterodimeric protein that is involved in many processes characterized by cellular stress, like ageing, chronic tissue inflammation, metabolic diseases, and cancer $[8,25]$. CLU mRNA is downregulated in the vast majority of naïve cancers according to Oncomine ${ }^{\circledR}$ database, and PCa does not make exception [6]. The analyses performed on the microarray dataset GSE6919 with GEO2R web tool showed that CLU expression is reduced in PCa in comparison to normal prostate tissue, following an ideal decreasing gradient from normal healthy prostate to epithelial tissues adjacent to primary tumors and then primary tumors up to metastases. Interestingly, the expression of NF$\kappa \mathrm{B}$ is significantly increased in metastases, where it inversely correlates with CLU expression. On the one hand, these results support early reports from our group $[15,16,26]$ and agree with the finding that histone tails modification, including $\mathrm{H} 3$ pan-deacetylation and $\mathrm{H} 3 \mathrm{~K} 27$ trimethylation as well as CpG island hypermethylation at the CLU promoter contribute to the epigenetic repression of this gene both in human PCa cell lines and in the TRAMP model $[17,27]$. On the other hand, the same results highlight that the inverse relation between CLU and $\mathrm{NF}-\kappa \mathrm{B}$ expression, previously noticed in CLUKO and TRAMP/CLUKO mice [20], can be extended from the animal model to the human disease.

Previously, some in vitro results have suggested that the relation between NF- $\kappa \mathrm{B}$ and CLU is complex, in that CLU is transcriptionally upregulated by NF- $\kappa \mathrm{B}[28]$ and, at the same time, intracellular CLU can inhibit NF- $\kappa \mathrm{B}$ activation by stabilizing the inhibitor $\mathrm{I} \kappa \mathrm{B}[7,11,12,29]$. In addition to the $\mathrm{I} \kappa \mathrm{B}$-mediated regulation of $\mathrm{NF}-\kappa \mathrm{B}$ nuclear translocation, several studies have shown that the NF- $\kappa$ B proteins are posttranslationally modified. These changes may directly control not only dimer interaction with other factors, their stability, and turnover but also may contribute to the selective regulation of NF- $\kappa \mathrm{B}$ transcriptional activity in a gene-specific manner. Altogether, these events contribute to a multifaceted NF- $\kappa$ B signaling control that is enormously more sophisticated than a simple on/off switch [30]. By gain-offunction and loss-of-function experiments in androgenindependent PCa cell line PC3, we demonstrated that CLU 

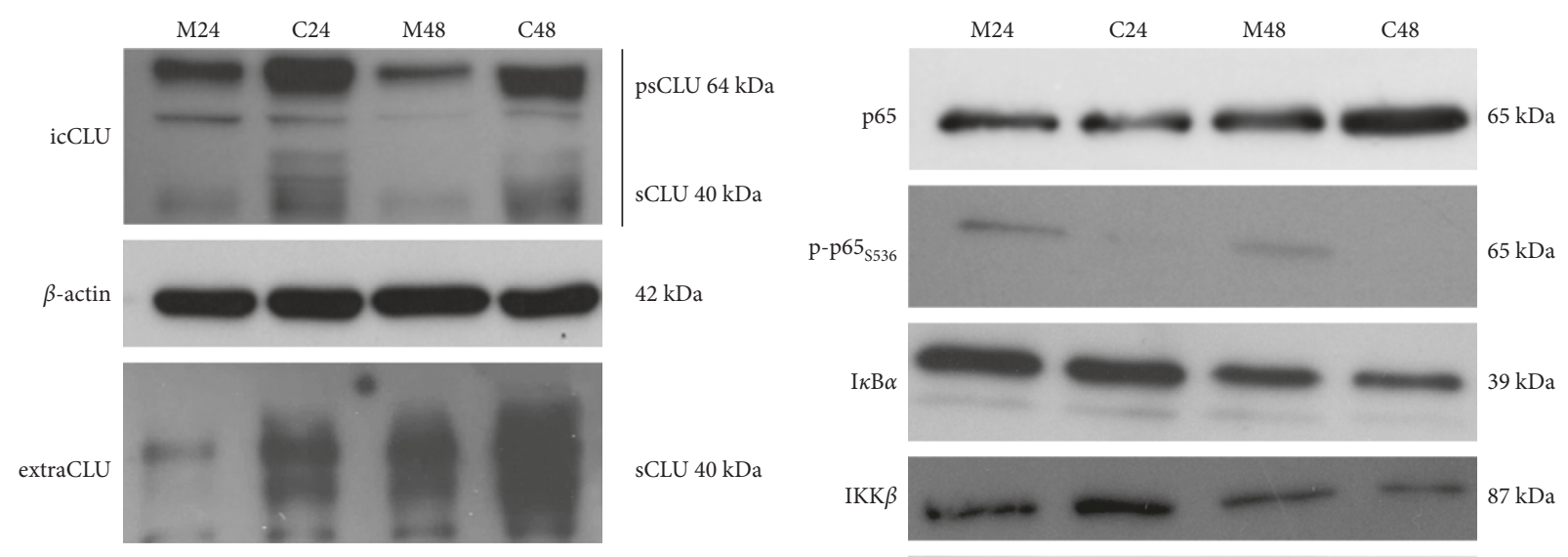

sCLU $40 \mathrm{kDa}$

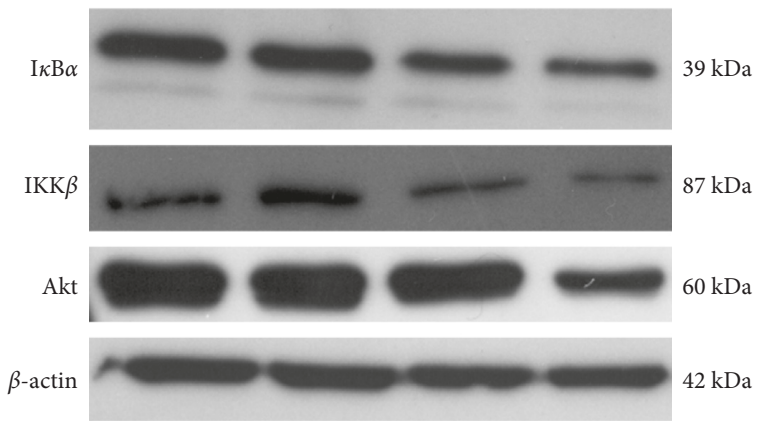

(a)

(b)

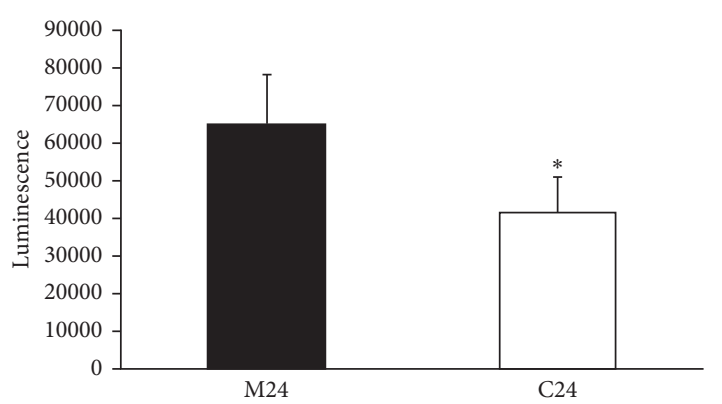

(c)

FIGURE 4: Effects of CLU transient overexpression on NF- $\kappa$ B activation. Quantification of CLU (a) and p65, p-p65 5536 , I $\kappa$ B $\alpha$, IKK $\beta$, and Akt (b) protein by WB analysis in PC3 cells transfected with pIRES-mock (M) or pIRES-CLU (C). The analysis was carried out in whole cell lysates, and cell culture media was collected 24 and 48 hours after transfection. $\beta$-Actin was used as loading control. icCLU, intracellular CLU; extraCLU, CLU secreted in culture media; psCLU, uncleaved CLU precursor, $64 \mathrm{kDa}$; sCLU, cleaved mature CLU, $40 \mathrm{kDa}$. The data shown are representative of three independent experiments. (c) Luciferase assay for NF- $\kappa$ B activity in PC3 cells cotransfected with pNF $\kappa$ BLUC plasmid and pIRES-mock (M24) or pIRES-CLU (C24). The assay was performed 24 hours after transfection. Mean normalized data of luminescence (arbitrary units) \pm SD from six replicate wells of three independent experiments are reported on the $Y$ axis. ${ }^{*} p<0.05$ vs. M24 (the unpaired Student's $t$-test).

expression is required to reduce the amount of constitutively active NF- $\kappa$ B, by decreasing $\mathrm{p}-\mathrm{p} 65_{\mathrm{S} 536}$, without significantly affecting $\mathrm{I} \kappa \mathrm{B} \alpha$ expression. Indeed, keeping in mind that $\mathrm{I} \kappa \mathrm{B} \alpha$ is a direct transcriptional target of NF- $\kappa \mathrm{B}$, the slight reduction of $\mathrm{I} \kappa \mathrm{B} \alpha$ measured in PC 3 cells overexpressing CLU 48 hours after transfection is a direct consequence of the inhibition of NF- $\kappa \mathrm{B}$ transcriptional activity measured in these cells [31, 32].

Indeed, following ectopic expression of CLU c-DNA, the expression of $\mathrm{p}-\mathrm{p} 65_{\mathrm{S} 536}$ is reduced along with p65 fraction translocated in the cell nuclei in comparison to empty vector transfected cells. The $S_{536}$ phosphorylation site is located in the transactivation domain of $\mathrm{p} 65$ and is conserved in both human and mouse [33]. It has been observed that the constitutive phosphorylation of $\mathrm{p} 65$ at serine $536\left(\mathrm{p}-\mathrm{p} 65_{5536}\right)$ affects the p65 dimer composition as well as the selective recruitment of phospho-p65 to specific promoters [34]. Of note, p-p65 $5_{536}$ is increased in patients carrying TMPrSS2/
ERG (T/E) fusion, the most common gene rearrangement in $\mathrm{PCa}$, where it is suggested to play a critical role in PCa tumorigenesis by enhancing the p65 transcriptional activity of both proinflammatory chemokines and ECM-modifying enzymes, thus producing a tumor-permissive microenvironment [35]. Under this experimental condition, the luciferase assay confirms a reduction of NF- $\kappa$ B transcriptional activity. The expression of NF- $\kappa \mathrm{B}$ transcribed genes involved in ECM degradation, such as MMP-9 and MMP-2, is consistently reduced. In order to exclude any possible bias coming from the unphysiological condition of protein overexpression, we integrated our experimental design with a complementary approach of gene function modulation by silencing CLU through siRNA oligonucleotides. After silencing CLU in PC3 cells, we observed opposite results compared to those detected in CLU overexpression models, i.e., an increase of p-p $65_{5536}$ and an increase of Nf- $\kappa \mathrm{B}$ activity accompanied by an increase of MMP-9 expression. Our 


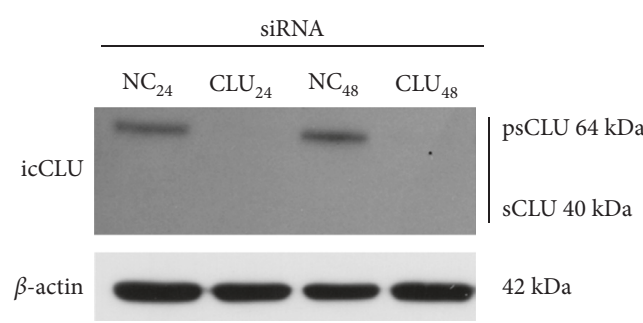

(a)

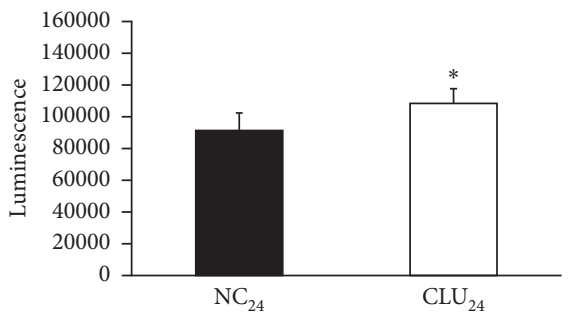

(c)

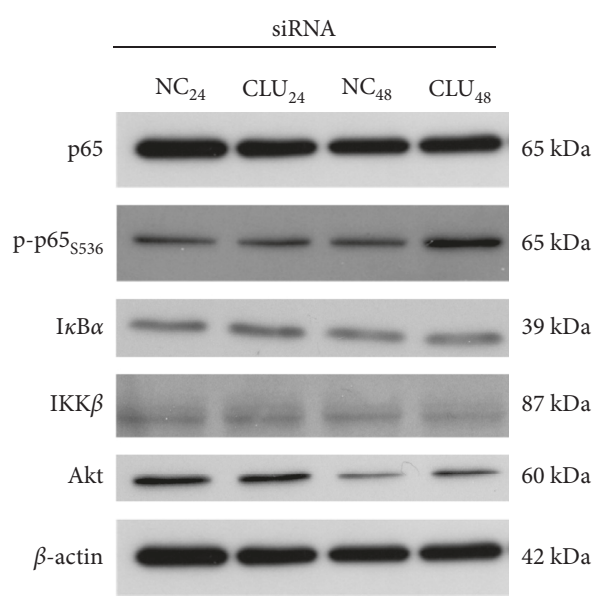

(b)

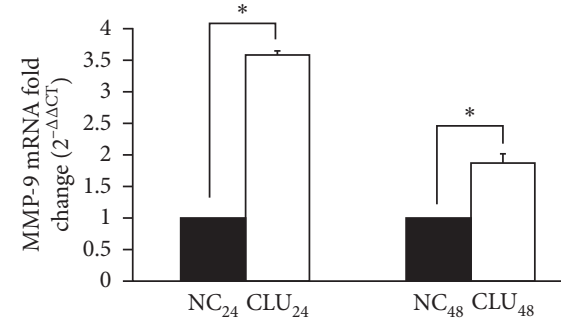

(d)

FIGURE 5: Effects of CLU silencing on p65 phosphorylation and NF- $\kappa \mathrm{B}$ activation. Quantification of CLU (a) or p65, p-p65 $5536, \mathrm{I} \kappa \mathrm{B} \alpha, \mathrm{IKK} \beta$, and Akt (b) protein by WB analysis in PC3 cells transfected with siRNA-CLU (CLU) or siRNA negative control (NC) in whole cell lysates 24 and 48 hours after transfection. $\beta$-Actin was used as loading control. icCLU, intracellular CLU; psCLU, uncleaved CLU precursor, $64 \mathrm{kDa}$; sCLU, cleaved mature CLU, $40 \mathrm{kDa}$. The data shown are representative of three independent experiments. (c) The luciferase assay for NF- $\kappa \mathrm{B}$ activity in PC3 cells cotransfected with pNF $\kappa$ B-LUC plasmid and siRNA-CLU or NC. The assay was performed 24 hours after transfection. Mean normalized data of luminescence (arbitrary units) \pm SD from six replicate wells of three independent experiments are reported on the $Y$ axis. ${ }^{*} p<0.05$ vs. M24 (the unpaired Student's $t$-test). (d) Quantification of MMP-9 mRNA by qPCR in PC3 cells transfected with siRNACLU or NC for 24 or 48 hours. $2^{-\Delta \Delta C T}$ values are reported on the $Y$ axis. GAPDH was used as the housekeeper gene. The value of MMP-9 expression in NC samples was fixed equal to 1. Error bars represent SD of three independent determinations each performed in duplicate. ${ }^{*} p<0.01$ vs. NC (the unpaired Student's $t$-test).

results are in good agreement with previous findings from other authors in different models [11,12,29]. A unique study showed that NF- $\kappa \mathrm{B}$ is activated by CLU-mediated stabilization of COMMD1, a protein that facilitates $\mathrm{I} \kappa \mathrm{B}$ ubiquitination and proteasomal degradation [36]. We observed that CLU regulates NF- $\kappa$ B activity by reducing p65 phosphorylation at $\mathrm{S}_{536}$. Because p-p65 $5_{\mathrm{S} 536}$ does not bind $\mathrm{I} \kappa \mathrm{B} \alpha$ nor is proteasome degraded, we suggest that CLU might inhibit NF- $\kappa$ B constitutive activation by an I $\kappa \mathrm{B}$-independent pathway [34]. The mechanism is supposed to be particularly relevant in androgen-independent cells such as PC3 and DU145 that constitutively express high levels of active Nf$\kappa \mathrm{B}$, being almost unresponsive to TNF $\alpha$ stimulation [37]. Based on the results of the IP analysis, we excluded a direct binding between CLU and p65 and suggest that CLU regulates the amount of intracellular $\mathrm{p}-\mathrm{p} 65_{\mathrm{S} 536}$ by regulating the activity of upstream kinases as IKK $\beta$ or Akt by a mechanism similar to that observed in cancer cells under growth-constraining condition [38]. This hypothesis is corroborated by the fact that Akt and IKK $\beta$ expression are reduced in PC3 cells overexpressing CLU for 48 hours in comparison to mock transfected controls. On the contrary, Akt expression is increased in PC3 cells silenced for CLU for 48 hours compared to NC-transduced control cells. Although the present study was conducted in a single cell line, which is in fact a limitation of the experimental design, we previously showed that CLU stable overexpression in prostate epithelial immortalized cells (PNTla) inhibits NF- $\kappa$ B activity by reducing Akt expression [20].

The finding that CLU reduces MMP-9 and MMP-2 expression by inhibiting NF- $\kappa \mathrm{B}$ is biologically relevant for $\mathrm{PCa}$ because these enzymes play a role in tumor dissemination by degrading ECM and basement membrane. Conflicting data have been reported about CLU effects on MMP expression in cultured cells. Administration of highly supraphysiological amounts of exogenous purified CLU in a murine macrophage cell line increased MMP-9 expression and activity. Disappointingly, no effects were observed following CLU silencing, questioning the specificity of the observed phenomena [39]. CLU increased MMP-2 expression in hepatocellular carcinoma cells [40], while CLU overexpression inhibited MMP-9 expression by reducing 

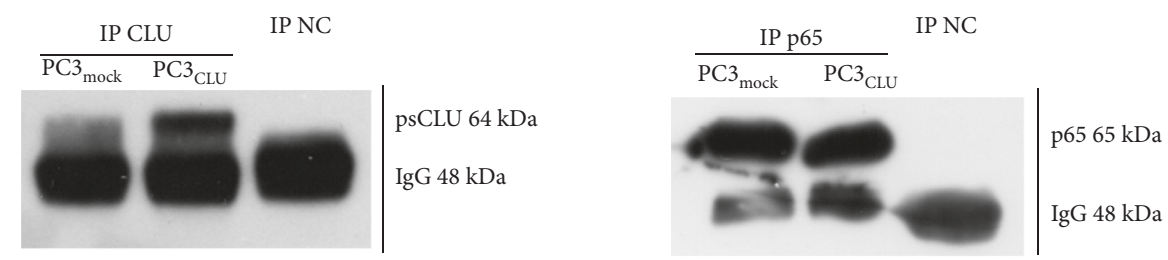

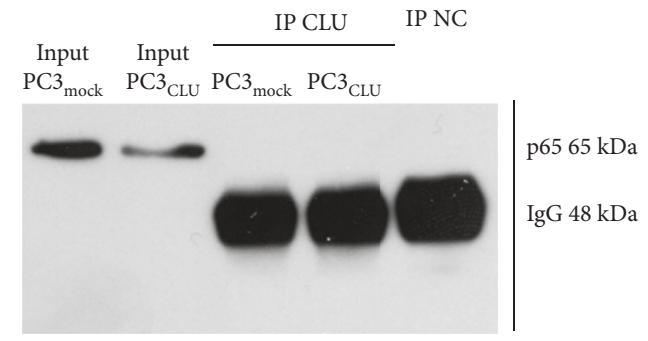

(a)

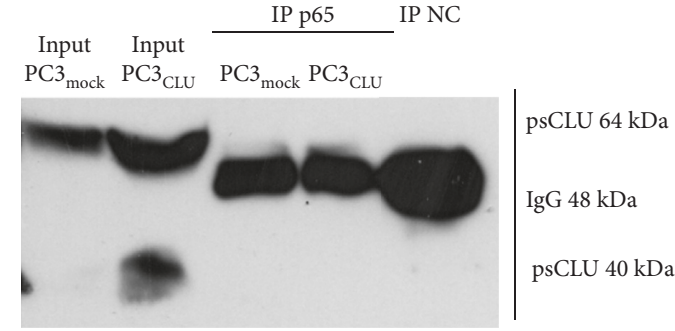

(b)

FIgURE 6: CLU and $\mathrm{p} 65$ interaction in $\mathrm{PC} 3_{\text {mock }}$ and $\mathrm{PC} 3_{\mathrm{CLU}}$ cells. Total proteins from $\mathrm{PC} 3_{\text {mock }}$ and $\mathrm{PC} 3_{\mathrm{CLU}}$ cells were immunoprecipitated with anti-CLU (IP CLU) (a) or anti-p65 (IP p65) (b) followed by WB with anti-p65 and anti-CLU antibodies. In parallel, immunoprecipitation with IgG was performed as negative control (IP NC). The specificity (negative control) and effectiveness (positive control) of the immunoprecipitation are shown in the upper panel of a and b. The interaction between CLU and p65 was evaluated comparing the amount of p65 recovered in the fraction immunoprecipitated with CLU (IP CLU) to the amount of p65 detected in the input whole cell lysate ((a), lower panel) or vice versa comparing the amount of CLU recovered in the fraction immunoprecipitated with p65 to the amount of CLU detected in the input whole cell lysate ((b), lower panel).

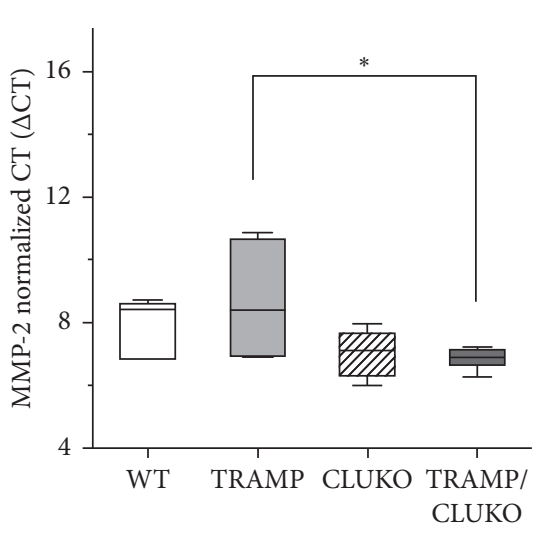

(a)

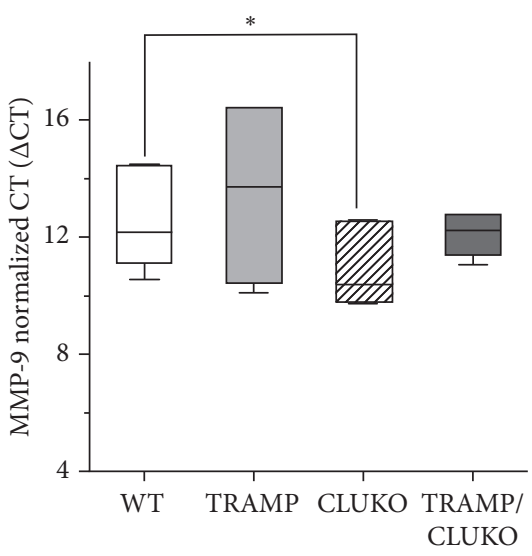

(b)

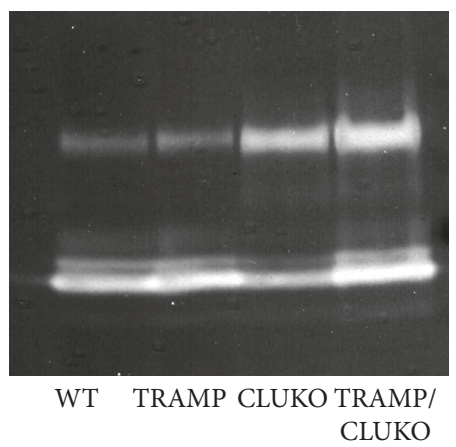

$125 \mathrm{kDa}$ MMP-9 dimers

$92 \mathrm{kDa}$ proMMP-9

$84 \mathrm{kDa}$ aMMP-9

$72 \mathrm{kDa}$ proMMP-2

$67 \mathrm{kDa}$ aMMP-2

(c)

FIGURE 7: Effects of CLU knockout on MMP-2 and MMP-9 expression and activity in vivo. Quantification of MMP-2 (a) and MMP-9 (b) mRNA in prostate samples of WT, TRAMP, CLUKO, and TRAMP/CLUKO mice. Number of animals in each group $=3$. $\Delta$ CT values are reported on the $Y$ axis. The $\mathrm{m}-\mathrm{GAPDH}$ was used as teh housekeeper gene. ${ }^{*} p<0.05$ (the Mann-Whitney $U$ test). (c) Gelatin zymography for MMP-2 and MMP-9 in prostate samples of WT, TRAMP, CLUKO, and TRAMP/CLUKO mice. The image shown is representative of three independent experiments. proMMP-9, uncleaved MMP-9; aMMP-9, cleaved active MMP-9; proMMP-2, uncleaved MMP-2; aMMP-2, cleaved active MMP-2. 
NF- $\kappa$ B activation in vascular smooth muscle cells [41]. CLU prevented stress-induced MMP-9 aggregation and activation of various MMP, both inside and outside human epithelial cells, by direct binding with the catalytic MMP domain [42]. To the best of our knowledge, our study is the first one to report the effects of CLU abrogation on MMP expression and activity in vivo, in a preclinical model of PCa. We found that MMP-2 and MMP-9 expression is higher in prostate samples from CLUKO and TRAMP/CLUKO mice in comparison to WT and TRAMP littermates. Moreover, the results of zymography assay show that MMP-2 and MMP-9 activity is higher in the prostate of CLU-null mice. These data are consistent with the observation that tumors in TRAMP/CLUKO mice showed increased tendency to metastasize when comparing with tumors in TRAMP mice expressing normal levels of CLU [20].

\section{Conclusions}

Overall, the presented data support the hypothesis that in normal physiological condition CLU participates to a negative loop in which transcriptional activation of CLU by NF- $\kappa \mathrm{B}$ is evoked to dampen the excessive constitutive activation of NF- $\kappa \mathrm{B}$ itself. When CLU expression is reduced in PCa by epigenetic mechanisms, the physiological brake on NF- $\kappa \mathrm{B}$ might be relieved. This effect is more important in the late PCa stage, when $\mathrm{Nf}-\kappa \mathrm{B}$ activity and expression reach the maximum. In fact, the increased NF$\kappa \mathrm{B}$ activity may cause an increased expression of proteases involved in ECM degradation that favors PCa progression towards a metastatic disease. Considering the important involvement of inflammatory processes in $\mathrm{PCa}$ onset and progression, the pharmacological strategies aimed at counteract epigenetic CLU downregulation in early stages of PCa could be crucial for effectively controlling the signaling pathways that lead to proliferation and invasion in advanced cancers.

\section{Data Availability}

No data were used to support this study.

\section{Conflicts of Interest}

The authors declare that there are no conflicts of interest regarding the publication of this paper.

\section{Authors' Contributions}

Aide Negri and Pierpaola Davalli contributed equally to this work.

\section{Acknowledgments}

V. N. was supported by a fellowship from Fondazione Umberto Veronesi. This work was partially supported by the Italian Ministry for Education University and Research, PRIN 2017, grant no. 2017T8CMCY.

\section{Supplementary Materials}

Figure S1: p65 expression and phosphorylation in additional PC3mock, PC3CLU, and p-p65S536 clones. Quantification of CLU, p65, and p-p65S536 protein by WB analysis in PC3CLU (namely, clones \#C5, \#C6, and \#C7) and PC3mock (namely, clone \#M4). Red Ponceau staining was used for loading and transfer control. icCLU, intracellular CLU; psCLU, uncleaved CLU precursor, $64 \mathrm{kDa}$; sCLU, cleaved mature CLU, $40 \mathrm{kDa}$. Figure S2: morphology, proliferation, and cell cycle analysis of PC3mock and PC3CLU clones. (a) Phase-contrast images of PC 3 cells, PC3mock, and PC3CLU. Magnification: 20×. (b) Cellular proliferation was assessed in PC3mock (black square) and in PC3CLU (white square) clones at the indicated time after seeding by crystal violet assay. Error bars represent SD of the mean of three PC3mock and three PC3CLU clones. ${ }^{*} p<0.05$ (the unpaired $t$-test vs. mock). (c) Cell cycle analysis was carried out in PC3mock and PC3CLU by FACS analysis. The graphs are representative of all the clones analyzed. The percentage of distribution of the cells in the cell cycle phases is reported in the table. Figure S3: expression of p65 in TRAMP and TRAMP/ CLUKO prostate tissues. Immunohistochemical staining of p65 in prostate tissues of 12- and 24-week-old (left and right panels, respectively) TRAMP and TRAMP/CLUKO mice. Three animals for each experimental group were examined. Images magnification 40×. (Supplementary Materials)

\section{References}

[1] L. M. Coussens and Z. Werb, "Inflammation and cancer," Nature, vol. 420, no. 6917, pp. 860-867, 2002.

[2] Y. Ben-Neriah and M. Karin, "Inflammation meets cancer, with NF- $\kappa \mathrm{B}$ as the matchmaker," Nature Immunology, vol. 12, no. 8, pp. 715-723, 2011.

[3] M. Karin, "Nuclear factor $-\kappa \mathrm{B}$ in cancer development and progression," Nature, vol. 441, no. 7092, pp. 431-436, 2006.

[4] D. P. Nguyen, J. Li, S. S. Yadav, and A. K. Tewari, "Recent insights into NF- $\kappa$ B signalling pathways and the link between inflammation and prostate cancer," BJU International, vol. 114, no. 2, pp. 168-176, 2014.

[5] P.-C. Chen, H.-C. Cheng, and C.-H. Tang, "CCN3 promotes prostate cancer bone metastasis by modulating the tumorbone microenvironment through RANKL-dependent pathway," Carcinogenesis, vol. 34, no. 7, pp. 1669-1679, 2013.

[6] F. Rizzi and S. Bettuzzi, "Clusterin (CLU) and prostate cancer," in Advances in Cancer Research, Vol. 105, Elsevier, Amsterdam, The Netherlands, 2009.

[7] G. Falgarone and G. Chiocchia, "Chapter 8 clusterin," in Advances in Cancer Research, Vol. 104, Elsevier, Amsterdam, The Netherlands, 2009.

[8] F. Rizzi and S. Bettuzzi, "The clusterin paradigm in prostate and breast carcinogenesis," Endocrine-Related Cancer, vol. 17, no. 1, pp. R1-R17, 2010.

[9] P. Nizard, S. Tetley, Y. Le Dréan et al., "Stress-induced retrotranslocation of clusterin/ApoJ into the cytosol," Traffic, vol. 8, no. 5, pp. 554-565, 2007.

[10] A. Wyatt, J. Yerbury, S. Poon, R. Dabbs, and M. Wilson, "Chapter 6 the chaperone action of clusterin and its putative role in quality control of extracellular protein folding," in Advances in Cancer Research, Vol. 104, Elsevier, Amsterdam, The Netherlands, 2009. 
[11] A. Essabbani, F. Margottin-Goguet, and G. Chiocchia, "Identification of clusterin domain involved in NF- $\kappa \mathrm{B}$ pathway regulation," Journal of Biological Chemistry, vol. 285, no. 7, pp. 4273-4277, 2010.

[12] G. Santilli, B. J. Aronow, and A. Sala, "Essential requirement of apolipoprotein $\mathrm{J}$ (clusterin) signaling for $\mathrm{I} \kappa \mathrm{B}$ expression and regulation of NF- $\kappa \mathrm{B}$ activity," Journal of Biological Chemistry, vol. 278, no. 40, pp. 38214-38219, 2003.

[13] L. McLaughlin, G. Zhu, M. Mistry et al., "Apolipoprotein J/ clusterin limits the severity of murine autoimmune myocarditis," Journal of Clinical Investigation, vol. 106, no. 9, pp. 1105-1113, 2000.

[14] V. Savkovic, H. Gantzer, U. Reiser et al., "Clusterin is protective in pancreatitis through anti-apoptotic and anti-inflammatory properties," Biochemical and Biophysical Research Communications, vol. 356, no. 2, pp. 431-437, 2007.

[15] M. Scaltriti, M. Brausi, A. Amorosi et al., "Clusterin (SGP-2, ApoJ) expression is downregulated in low- and high-grade human prostate cancer," International Journal of Cancer, vol. 108, no. 1, pp. 23-30, 2004.

[16] F. Rizzi, L. Belloni, P. Crafa et al., "A novel gene signature for molecular diagnosis of human prostate cancer by RT-qPCR," PLoS One, vol. 3, p. e3617, 2008.

[17] H. E. Rauhala, K. P. Porkka, O. R. Saramäki, T. L. J. Tammela, and T. Visakorpi, "Clusterin is epigenetically regulated in prostate cancer," International Journal of Cancer, vol. 123, no. 7, pp. 1601-1609, 2008.

[18] A. Caporali, P. Davalli, S. Astancolle et al., "The chemopreventive action of catechins in the TRAMP mouse model of prostate carcinogenesis is accompanied by clusterin over-expression," Carcinogenesis, vol. 25, no. 11, pp. 2217-2224, 2004.

[19] A. Thomas-Tikhonenko, I. Viard-Leveugle, M. Dews et al., "Myc-transformed epithelial cells down-regulate clusterin, which inhibits their growth in vitro and carcinogenesis in vivo," Cancer Research, vol. 64, no. 9, pp. 3126-3136, 2004.

[20] S. Bettuzzi, P. Davalli, S. Davoli et al., "Genetic inactivation of ApoJ/clusterin: effects on prostate tumourigenesis and metastatic spread," Oncogene, vol. 28, no. 49, pp. 4344-4352, 2009.

[21] M. Scaltriti, S. Bettuzzi, R. M. Sharrard, A. Caporali, A. E. Caccamo, and N. J. Maitland, "Clusterin overexpression in both malignant and nonmalignant prostate epithelial cells induces cell cycle arrest and apoptosis," British Journal of Cancer, vol. 91, no. 10, pp. 1842-1850, 2004.

[22] N. M. Greenberg, F. DeMayo, M. J. Finegold et al., "Prostate cancer in a transgenic mouse," Proceedings of the National Academy of Sciences, vol. 92, no. 8, pp. 3439-3443, 1995.

[23] A. Modernelli, V. Naponelli, M. Giovanna Troglio et al., "EGCG antagonizes Bortezomib cytotoxicity in prostate cancer cells by an autophagic mechanism," Scientific Reports, vol. 5, no. 1, p. 15270, 2015.

[24] S. Huang, C. A. Pettaway, H. Uehara, C. D. Bucana, and I. J. Fidler, "Blockade of NF- $\kappa$ B activity in human prostate cancer cells is associated with suppression of angiogenesis, invasion, and metastasis," Oncogene, vol. 20, no. 31, pp. 4188-4197, 2001.

[25] I. P. Trougakos and E. S. Gonos, "Chapter 9 oxidative stress in malignant progression," in Advances in Cancer Research, Vol. 104, Elsevier, Amsterdam, The Netherlands, 2009.

[26] S. Bettuzzi, P. Davalli, S. Astancolle et al., "Tumor progression is accompanied by significant changes in the levels of expression of polyamine metabolism regulatory genes and clusterin (sulfated glycoprotein 2) in human prostate cancer specimens," Cancer Research, vol. 60, no. 1, pp. 28-34, 2000.
[27] M. Bonacini, M. Coletta, I. Ramazzina et al., "Distinct promoters, subjected to epigenetic regulation, drive the expression of two clusterin mRNAs in prostate cancer cells," Biochimica et Biophysica Acta (BBA)-Gene Regulatory Mechanisms, vol. 1849, no. 1, pp. 44-54, 2015.

[28] X. Li, P. E. Massa, A. Hanidu et al., "IKK $\alpha$, IKK $\beta$, and NEMO/ IKK $\gamma$ are each required for the NF- $\kappa \mathrm{B}$-mediated inflammatory response program," Journal of Biological Chemistry, vol. 277, no. 47, pp. 45129-45140, 2002.

[29] V. Devauchelle, A. Essabbani, G. De Pinieux et al., "Characterization and functional consequences of underexpression of clusterin in rheumatoid arthritis," The Journal of Immunology, vol. 177, no. 9, pp. 6471-6479, 2006.

[30] F. Christian, E. Smith, and R. Carmody, "The regulation of NF$\kappa \mathrm{B}$ subunits by phosphorylation," Cells, vol. 5, no. 1, p. 12, 2016.

[31] S. Sun, P. Ganchi, D. Ballard, and W. Greene, "NF- $\kappa$ B controls expression of inhibitor $\mathrm{I} \kappa \mathrm{B} \alpha$ : evidence for an inducible autoregulatory pathway," Science, vol. 259, no. 5103, pp. 1912-1915, 1993.

[32] K. Brown, S. Park, T. Kanno, G. Franzoso, and U. Siebenlist, "Mutual regulation of the transcriptional activator NF- $\kappa \mathrm{B}$ and its inhibitor, $\mathrm{I} \kappa \mathrm{B} \alpha$," Proceedings of the National Academy of Sciences, vol. 90, no. 6, pp. 2532-2536, 1993.

[33] L. Vermeulen, G. De Wilde, S. Notebaert, W. Vanden Berghe, and G. Haegeman, "Regulation of the transcriptional activity of the nuclear factor- $\kappa \mathrm{B}$ p65 subunit," Biochemical Pharmacology, vol. 64, no. 5-6, pp. 963-970, 2002.

[34] C. Y. Sasaki, T. J. Barberi, P. Ghosh, and D. L. Longo, "Phosphorylation of RelA/p65 on Serine 536 defines an IкBaindependent NF- $\kappa$ B Pathway," Journal of Biological Chemistry, vol. 280, no. 41, pp. 34538-34547, 2005.

[35] L. Zhang, L. Shao, C. J. Creighton et al., "Function of phosphorylation of NF- $\kappa \mathrm{B}$ p65 ser536 in prostate cancer oncogenesis," Oncotarget, vol. 6, no. 8, pp. 6281-6294, 2015.

[36] A. Zoubeidi, S. Ettinger, E. Beraldi et al., "Clusterin facilitates COMMD1 and I-B degradation to enhance NF-B activity in prostate cancer cells," Molecular Cancer Research, vol. 8, no. 1, pp. 119-130, 2010.

[37] V. Gasparian, Y. J. Yao, D. Kowalczyk et al., "The role of I $\kappa \mathrm{K}$ in constitutive activation of NF- $\kappa \mathrm{B}$ transcription factor in prostate carcinoma cells," Journal of Cell Science, vol. 115, no. 1, pp. 141-151, 2002.

[38] H. Jo, Y. Jia, K. K. Subramanian, H. Hattori, and H. R. Luo, "Cancer cell-derived clusterin modulates the phosphatidylinositol 3'-kinase-Akt Pathway through attenuation of insulinlike growth factor 1 during serum deprivation," Molecular and Cellular Biology, vol. 28, no. 13, pp. 4285-4299, 2008.

[39] Y.-J. Shim, B.-H. Kang, H.-S. Jeon et al., "Clusterin induces matrix metalloproteinase-9 expression via ERK1/2 and PI3K/ Akt/NF- $\kappa$ B pathways in monocytes/macrophages," Journal of Leukocyte Biology, vol. 90, no. 4, pp. 761-769, 2011.

[40] J. Zhong, X. Yu, X. Dong et al., "Therapeutic role of meloxicam targeting secretory clusterin-mediated invasion in hepatocellular carcinoma cells," Oncology Letters, vol. 15, no. 5, pp. 7191-7199, 2018.

[41] H.-J. Kim, E.-K. Yoo, J.-Y. Kim et al., "Protective role of clusterin/ apolipoprotein $\mathrm{J}$ against neointimal hyperplasia via antiproliferative effect on vascular smooth muscle cells and cytoprotective effect on endothelial cells," Arteriosclerosis, Thrombosis, and Vascular Biology, vol. 29, no. 10, pp. 1558-1564, 2009.

[42] S. Jeong, D. R. Ledee, G. M. Gordon et al., "Interaction of clusterin and matrix metalloproteinase- 9 and its implication for epithelial homeostasis and inflammation," The American Journal of Pathology, vol. 180, no. 5, pp. 2028-2039, 2012. 


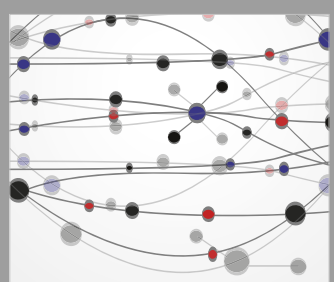

The Scientific World Journal
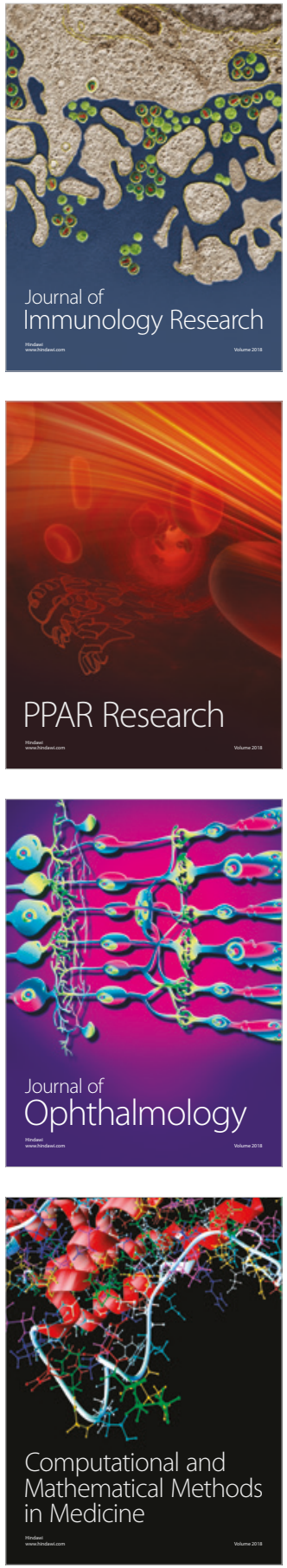

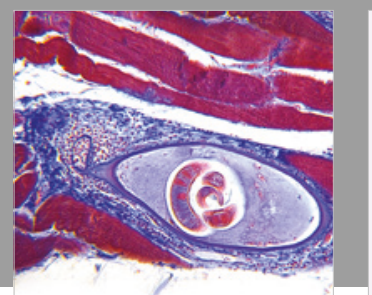

Gastroenterology Research and Practice

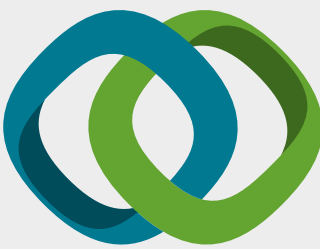

\section{Hindawi}

Submit your manuscripts at

www.hindawi.com
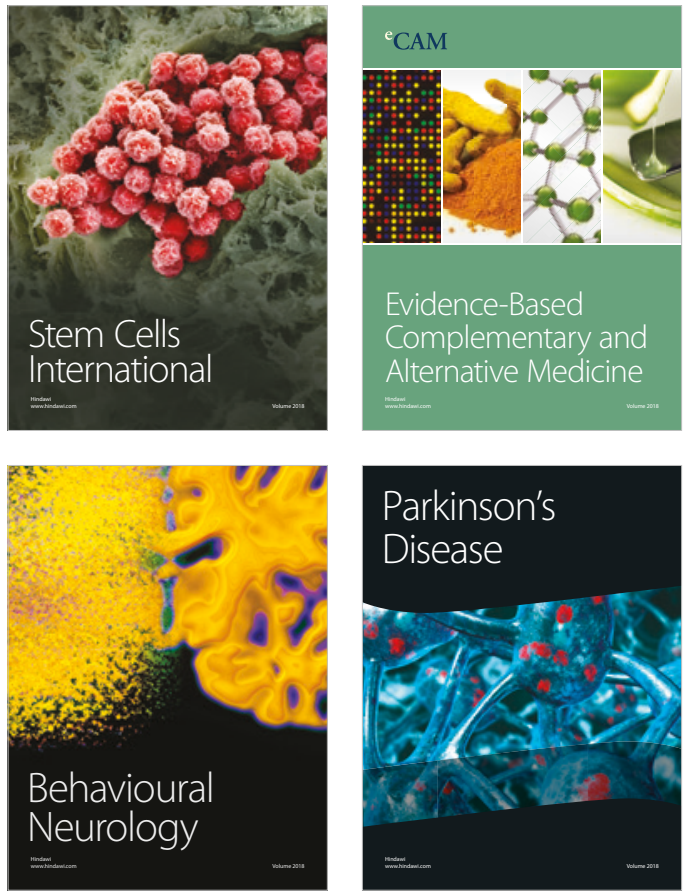

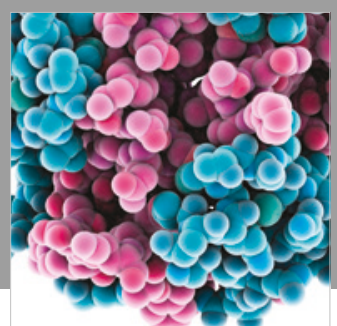

ournal of

Diabetes Research

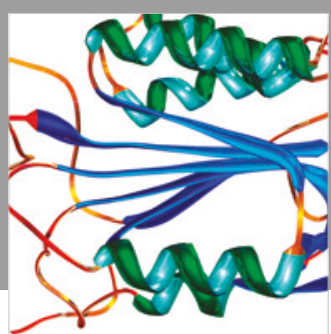

Disease Markers
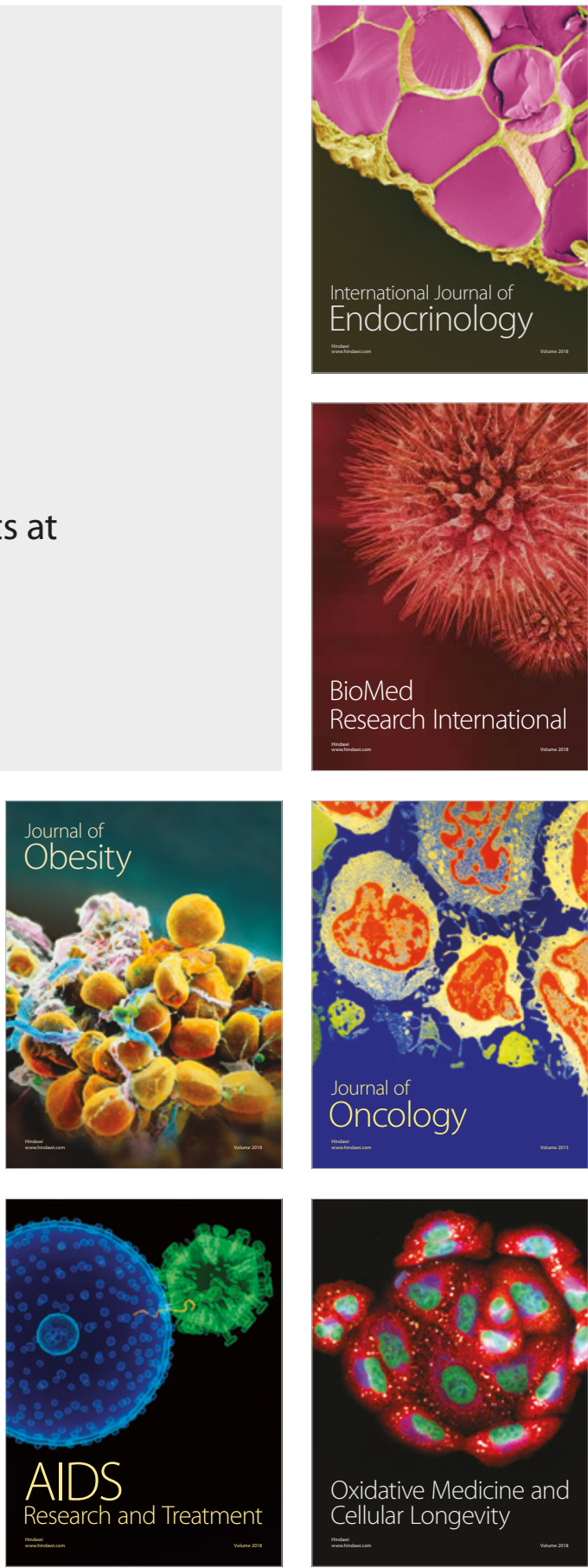